\title{
Linking Agriculture and Nutrition Security through Transforming the Food Value Chain
}

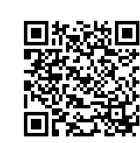

\author{
Jamuna Prakash* \\ ${ }^{1}$ Visiting Professor, International Academy of Food Science and Technology, Canada. \\ ${ }^{2}$ Former Professor, Department of Food Science and Nutrition, University of Mysore, Mysuru, India.
}

Submission: January 08, 2018; Published: February 20, 2018

*Corresponding author: Jamuna Prakash, (Visiting Professor, International Academy of Food Science and Technology, Canada), Department of Food Science and Nutrition, University of Mysore, Mysuru, India, Email: jampr55@hotmail.com

\begin{abstract}
Agriculture is the foundation for food and nutrition security. The food value chain encompasses the journey of agricultural commodities from farm - from the stage of harvest to ready-to-eat product. During this process of multiple stages and handlers, the journey can be short, when the commodities are meant for domestic consumption with primary processing, or long wherein a processed, packaged product is placed on the market shelf. During this journey there are alterations in the composition and characteristics of the product, which define their value for target population. The food value chain is an important influencing factor for health of population through direct linkage to food and nutrition security. Nearly 1/3rd of world population is malnourished as per recent Global Nutrition Report and most of it comes from middle and low income countries. Nearly 800 million are calorie deficient, and stunting is seen in 159 million children. On the other side, there are also increasing incidences of non-communicable diseases with 2 billion adults coming under the category of either overweight or obese, and one in twelve suffering with type 2 diabetes. Efforts are needed to strengthen the food value chain to minimize food losses and connect agriculture to nutrition. With diet as number one factor on global burden of disease, changes in food production, food storage and distribution, cross border trade, food packaging and processing could have a significant impact on diet and nutrition related issues. The program actions could emphasize improved food handling and storage to reduce wastage, control or regulation of trade for equi-distribution of resources, identification of beneficiaries along the food chain for legitimate receipt of benefits, improved processing to retain and enhance nutrition appropriate to achieve food and nutrition security, as well as to strengthen food regulatory laws to focus on safe food both through food industries and catering institutions.

Keywords : Agriculture production; Food losses; Healthy foods; Nutritional deficiencies; Processed foods
\end{abstract}

\section{Introduction}

Agriculture is the mainstay of human survival. In an average household, the daily happenings revolve around chores related to food, be it planning, marketing, and preparation, eating or cleaning. The expenditure towards food is primary requisite, which cannot be ignored. The agriculture commodities undergo many stages of transformations when they finally reach the plate. There may not be any food, which has not undergone any processing before it is eaten, even a ready to eat fruit or vegetables is washed and/or cut before it is eaten. These actions alter the quality of food, both negatively and positively, and thus influence the nutrient intake of populations [1].

\section{Agriculture and Food Security}

Adequate food and clean potable water are issues of basic rights. Agriculture, nutrition and social protection have clear linkages: adequate levels of food production are the first necessary steps to ensure the availability of nutritious foods for consumption. Food security refers to continuous availability and accessibility of adequate food at all times. At the same time it should be affordable by all section of population. While the earlier definitions of food security did not refer to quality of diets, the concept of quality was added later to ensure the nutritional adequacy of diets as the mere availability of food in sufficient quantity was not in tune with the nutritional requirements of human body. However, whether it is the quantity or quality of food, both are directly linked to agricultural production [2].

Looking at the current agriculture production, the world grain production stands at nearly 2,500 million tons, of which $43 \%$ is used for human food purposes, while the rest goes for industrial or for feeding animals. Production wise, the figure looks adequate, however, despite it; the number of hungry population is over 800 million indicating that there are issues with food availability, distribution or maybe affordability. It may also be noted that the countries involved in agriculture are far lesser than the countries with no agriculture implying that producing countries also take care of non- producing countries by way of export. Mean per capita consumption of food grain comes up to $150 \mathrm{~kg}$ per person per year according to current production, though there could be major variations among populations in quantities depending upon the food habits. In some countries grains are replaced by meat foods to a larger extent, whereas in some grains may be the only major staples. 
India is a country with agriculture dominance, and at a glance, the food production seems to be sufficient at present. The current grain production is around 252 million tons indicating sufficiency. India has also progressed well in production of fruits and vegetables, nearly being number one in the world, and milk has been topping the chart for many years now on account of white revolution. Hence while food production is not an issue, adequate availability and food distribution are the issues compromising intake of adequate diets. The Government has put in many programs to alleviate the food insecurity by offering subsidized food grains for families coming from below poverty line. The scenario repeats in many countries with varying levels of agricultural production.

There are also questions raised on adequate quality of diets, which is linked to planned agriculture. Since the farmers try to grow according to the demands of market, which always is not predictable, we encounter a glut production. We have recently witnessed this with tomatoes, onions and brinjals. When this happens, then farmers losses heavily and the produce gets wasted to a considerable extent. This is where a planned agriculture is needed. Planning has to take into account the need of a particular commodity by population keeping in mind the desirable diets and not just the food habits or culture. A good example of these is pulses, which are a primary commodity in our diet patterns. The pulse production has always been much less than what is needed and this has been evident with a continuous exorbitant rise in the cost of pulses and the need to import it from other countries to meet the demand.

\section{The Food Supply Chain and Food Security}

The supply chain includes the transport of raw produce to the intended recipient through the market. While in this supply chain there can be one more intermediary, the food manufacturer. Whoever the end-recipient maybe, the retention of quality in the supply chain is very crucial to prevent losses. Apart from reducing the visual, sensory, and keeping quality of produce, it can bring down the nutritional quality thus causing an unnecessary nutritional loss. The recent FAO report indicates that there are considerable losses of food in developing countries on account of mishandling. These are losses before the produce is subjected to processing. Whereas in developing countries more of food losses are from the processed foods category. Hence these would include the losses on account of extra burden of resources utilized for processing foods namely - human resources, energy, packaging, transport, marketing efforts, in such cases it is a waste of all inputs [3].

\section{Processed Foods and Food and Nutrition Security}

Food processing plays a very crucial role in preventing food losses and waste by way of processing foods and increasing their shelf life. They are a valuable and essential chain in the link of value addition. In the current scenario, we are witnessing two types of food processers, one which deals with processed and packaged foods with a considerable extension of shelf life, while the other deals with catered a food which has gained a huge market share during recent years. Especially in urban area, more and more people depend on foods prepared outside the family kitchen. In both the sectors technologies need to focus on retention of nutritional value of foods as is possible with optimum process conditions selected. At the same time, all levels of processing need good manufacturing and hygienic practices to comply with food safety regulations. Food business operators are responsible for ensuring the safety of food supplied to all consumers irrespective of the type or size of business operation. Food manufacturing sector puts forward many opportunities for value addition to support nutrition, whether in selection of healthy ingredients, better technologies, introduction of fortified foods based on public health situations, etc. [4].

\section{Incorporating Health in Foods to Counter the Nutrition Insecurity}

Since one of the prominent dietary changes brought about by dietary transition is dependence on processed foods, all food manufacturers can be a part of process of incorporation of health in foods. It is very well known that most of the processed foods use refined ingredients, are rich is fat, salt and sugar and many chemical additives, healthful foods would require use of whole grains cereals, reduction of fat, salt, and sugar levels in foods, minimum processing to retain nutritional value as much as possible, and introduction of more healthy choices to discourage purchase of unhealthy foods. Consumer educations through label declarations, as well as through the use of social media are all possible measures to incorporate health in processed foods.

\section{Food Choices}

Human body needs the nutrients, carbohydrates, proteins, fats, vitamins and minerals which are provided in the form of foods. The food is eaten in response to biological needs. There are plenty of foods available to select from, however selection and consumption of foods depends on the attitudes, beliefs, social interactions and behavioral economics of food choices the food environment or in other words, the food availability plays a significant role in decision making in food behavior. Early studies focused on individual foods, single nutrients, and dietary ingredients with specific health outcomes while the current trend is to analyze food patterns rather than nutrients in relation to health and well being. The validity of this approach is borne by the fact that foods are not eaten alone, but as part of diet hence the totality of diet becomes more important.

We need to consider the consumer's adoption of nutritional recommendations and healthy foods - How much would consumers respond to the changes brought about by increasing the choices for healthy foods? While the answer is difficult, it 
would depend on the consumer's awareness, the knowledge level, the willingness to adopt a change and voluntary replacement of so called unhealthy foods with healthy foods. While the role of food industry is to put healthy foods on market shelf, the nutritionists could engage in spreading the relevant awareness. The dynamics of food choices are influenced by the industry.

\section{Nutritional Challenges}

Swaminathan defined nutrition security as, 'Physical, economic and social access to a balanced diet, safe drinking water, environmental hygiene, primary health care and primary education'. This latter definition of nutrition security involves both food and non-food factors. Under nutrition does not affect only the health and well being of individual children, it also undermines the strength of their societies. There has been a reduction in malnutrition, however, the pace/rate of reduction is not adequate enough. Investment in nutrition is very critical to future economies of nation. It paves way for 'gray matter infrastructure' which is important for countries dealing with knowledge based economies.

The nutrition security needs to be strengthened in view of prevailing nutritional deficiencies, excesses and imbalances. According to recent Global Nutrition Report, (2016) [5] nearly $1 / 3 \mathrm{rd}$ of world population at present is malnourished. Most of the malnourished people come from middle and low income countries. Nearly 800 million are calorie deficient, and stunting is seen in 159 million children. On the other side, there are also increasing incidences of non-communicable diseases with 2 billion adults coming under the category of either overweight or obese, and one in twelve suffering with type 2 diabetes. In terms of ranking, among 132 countries, India is placed on 114th rank for stunting with prevalence rate of $38.7 \%$, and 120 th rank for wasting with prevalence rate of $15.1 \%$. The prevalence rate of anemia is ever high among women of reproductive ages with 170 th ranking and $48.1 \%$ of prevalence among 185 countries. Among non-communicable diseases the prevalence of diabetes is particularly high with $9.5 \%$ at 104 th rank among 190 countries. Almost all of these require immediate attention and millennium development goals were directed towards them, though most of them were not achieved by many countries. Now, we look forward to sustainable develop goals for bettering lives on earth, most of which are related to nutrition in some way or other. For example, good nutrition increases earning capacity and supports productive lives to achieve the target of 'no poverty' and 'zero hunger'. Good nutrition drives up IQ levels through appropriated cognitive development and supports women's development for achieving quality education and gender equality.
The agriculture demand is also impacted by the demographic transition. Indian population stands at 1.34 billion and may stabilize at 1.5 billion around 2030. The number of people in productive years will also undergo a change with less number of people in productive years and more number of dependents. The food production needs to keep pace with increasing population. There needs to be a policy shift in Agriculture to augment production of quality foods.

The agriculture challenges are adequate production to keep pace with increasing population, harmony in demand and supply to prevent mismatch resulting in loss to farmer, improving the improper storage conditions, decreasing area under cultivation, decreasing available water and other resources, changing climate, resistant pests, deceasing diversity, increasing food costs and factory farming of animals [6].

A political will to make smart commitments towards achieving nutrition goals as per Global Nutrition report suggests establishment of SMART (specific, measurable, achievable, relevant, and time bound) national targets for stunting, wasting, exclusive breastfeeding, low birth weight, anemia, childhood overweight, adult obesity, diabetes and salt reduction by all National government. This also includes setting up of nutrition sensitive water, sanitation and hygiene to lower the infections especially among young children. In addition, appropriate investment on education and health sector is also emphasized. In conclusion, the food value chain can be an important means of achieving food and nutrition security among population groups.

\section{References}

1. UNSCN (2011) Progress in Nutrition, $6^{\text {th }}$ Report on the World Nutrition Situation. United Nations System Standing Committee on Nutrition, WHO, Geneva, Switzerland.

2. World Health Organization and United Nations Children's Fund (2004) Focusing on anaemia. Towards an integrated approach for effective anaemia control. Geneva, Switzerland.

3. WHO, FAO, UNICEF, GAIN, MI, FFI (2009) Recommendations on wheat and maize flour fortification. Meeting Report: Interim Consensus Statement. Geneva, Switzerland.

4. Pacho'n H, Spohrer R, Mei Z, Serdula MK (2015) Evidence of the effectiveness of flour fortification programs on iron status and anemia: a systematic review. Nutr Rev 73(11): 780-795.

5. IFPRI (2016) Global Nutrition Report 2016: From promise to impact: Ending malnutrition by 2030. International Food Policy Research Institute. Washington DC, USA.

6. HLPE (2014) Food losses and waste in the context of sustainable food systems. A Report by the High Level Panel of Experts on Food Security and Nutrition of the Committee on World Food Security. 
This work is licensed under Creative Commons Attribution 4.0 License DOI: $10.19080 /$ NFSIJ.2018.05.555665
- Quality Editorial service

- Swift Peer Review

- Reprints availability

- E-prints Service

- Manuscript Podcast for convenient understanding

- Global attainment for your research

- Manuscript accessibility in different formats

( Pdf, E-pub, Full Text, Audio)

- Unceasing customer service

Track the below URL for one-step submission https://juniperpublishers.com/online-submission.php 